\title{
A support group for women psychiatrists
}

\author{
JANe Bernal, Clinical Lecturer in the Psychiatry of Mental Handicap, Cambridge \\ University Department of Psychiatry, Addenbrooke's Hospital, Cambridge \\ CB2 2QQ (correspondence), formerly Royal Free Hospital; ABIGAIL SELTZER, \\ Institute of Psychiatry, London SE5 8AF, formerly Royal Free Hospital; CAROL \\ HARVEY, Senior Registrar, Charing Cross Hospital, London W6 8RP, formerly \\ Royal Free Hospital; Jill Livingstone, Senior Registrar, Royal Free Hospital, \\ London NW3 2QG; JANET CARRICK, Senior Registrar, Maudsley Hospital, London \\ SE5 8AZ, formerly Royal Free Hospital; and JoY DALTON, Consultant, Whittington \\ Hospital, London N19
}

We were members of a support group for women psychiatrists which we found rewarding and which stimulated us to question many assumptions. We describe our experiences in the hope that trainees and consultants alike will consider the potential of similar groups in their own working lives.

\section{The group's formation}

The group began in 1983, meeting fortnightly over four and a half years, while we worked mainly in hospitals on the Royal Free rotation. There were several reasons for starting the group. We believe that all doctors and especially psychiatrists need emotional support as we work with distressed patients and have to cope with the powerful feelings this arouses. Before our group began support within our training scheme was haphazard and diffuse. Most of us were new to psychiatry and the problems facing new trainees have been well documented.

There were specific reasons for starting a women only group. There is still a limited range of role models for women among senior psychiatrists. This made us question the directions in which our careers could develop and how we could combine career and other commitments. We also found that women were more able than men to acknowledge their need for support. Several mixed sex groups were, in fact, started at about the same time as ours but none survived when the members moved within the rotation. Moreover, being both psychiatrists and women gave us more in common, making it easier to tolerate other differences.

Women also share certain experiences which shape their attitudes differently from men's. For example, we remember a video teaching session where trainees watched a mental state being elicited from a male in-patient. He had seriously sexually assaulted a woman, and was preoccupied by ideas of rape and assault. He admitted to regularly following women in a local shopping centre. All the women present felt that the management of the patient was more pressing than detailed phenomenology and were astonished that he was allowed such freedom that women were at risk of attack. All but one of the men in the group viewed this response as 'hysterical' and 'overemotional'. Afterwards this became a focus of discussion for women throughout the rotation and was one of the issues leading to the setting up of our group.

The group began by inviting women psychiatrists associated with the rotation to the Women's Therapy Centre. Some dozen trainees and one consultant met one of the Centre's therapists, described their experiences as women in psychiatry and welcomed the therapist's offer to facilitate further meetings at the Centre.

\section{The early stages}

We explored various methods of functioning with the therapist and decided that we aimed to become a selfhelp group but needed her assistance at first. We nominated topics for discussion, such as why we had chosen psychiatry; meeting simply for our own needs seemed self-indulgent. Having a structure reduced our anxieties, while discussing work-related topics reassured us that we were meeting for valid reasons. Within this framework we experimented with different techniques, including role-play - and paired listening.

After the initial months we were raising more personal matters. For instance, a talented artist revealed how torn she felt by conflicting wishes to paint and work in psychiatry: this found echoes in other group members who faced competing demands. The therapist helped us concentrate on our feelings without adopting the familiar doctor role as a defence. She pointed out that the group was becoming more therapeutic and supportive, less concerned with information exchange. Creating safety within the group 
then became paramount. We agreed that personal information would not go further, and that meetings outside must not continue group work.

Apportioning time also created difficulties which were partially resolved by 'going round' at the beginning of every meeting, giving each member time to relate the past fortnight's happenings and her current preoccupations. This provided a way of setting aside the day's events to concentrate on the group. Following this structured opening, members were free to raise their own concerns, or prompt others. Similarly, at the end each summarised how she now felt, minimising the amount of unfurnished business carried through the next fortnight.

Each member now recognised she had a responsibility for the group as a whole, and for herself within it. We felt able to continue without the therapist and left the Women's Therapy Centre and met in rotation in members' homes.

\section{The middle stages}

As we got to know one another, we became more interested in issues that did not directly involve work. We began to tell our life stories, which revealed many differences between us in terms of class origins, religious and political views, sexual orientation and current circumstances. By this stage, however, group membership itself gave a feeling of unity. Although at times each of us felt isolated from the rest of the group, each was as often astonished to find someone else with almost identical feelings and experiences.

These histories were also fascinating because they illuminated previously recounted work difficulties. One woman, working in old age psychiatry, had spoken of experiencing enormous sadness whenever a severely demented patient died. The degree of her distress became comprehensible as she described her own father's last illness.

After this, we left predetermined topics, concentrating on issues arising at the start of each session. In the group, members assumed various roles. As often happens in self-help groups, each became the therapist at different times. Sharing this role also absolved our consultant member from feeling she should adopt it.

We tried to deal with the strong emotions which membership changes aroused by anticipating and discussing them. By this time, more new women had entered the rotation. We were unsure about inviting them to join us, as our newer members had felt they were entering a tight clique. Moreover, having shared our histories, admitting new members would mean starting again for us, while newcomers might never feel they belonged. Feeling somewhat guilty about those we were excluding, we closed the group.

\section{The end stages}

For four years 'going round' at the beginning and end of each session had partially resolved competition for time, but emphasised 'acute' issues at the expense of serious but less urgent concerns. This eventually became a pressing problem when a member repeatedly tried unsuccessfully to raise a subject of personal importance. We began to reflect on whether the group was still worthwhile.

We invited our therapist back for a discussion on the group's future. Three options emerged: to open up to new members; to become a formal "therapy" group; or to end. With the therapist's help, we saw that ending might be a positive choice not an admission of defeat. After some difficult meetings, we accepted that the group had reached the end of its useful life, and agreed to work towards ending, however painful this was. Some felt hostility towards those who had expressed discontent, or had left earlier, but despite this, we achieved our goals of attending to unfinished business and ending without recriminations.

\section{Comment}

Since it finished we can see the group's value more clearly. It fulfilled its support function, enabling us to manage our own and our patients' feelings without being overwhelmed or losing the ability to empathise. We discovered that we could function well without being perfect.

Some of us had known other women's groups, and most brought a feminist perspective which was increasingly valued and shared. Many practices, in psychiatry as elsewhere, restrict the choices open to women. We have, for example, observed that less official help is given to women who care for a disabled relative than to their male counterparts. Women doctors are still being asked at interview about their child-care, despite sex discrimination legislation. The group gave us the strength to challenge such practices and the underlying attitudes. Tasks traditionally performed by women tend to be undervalued financially and socially. Psychiatrists may share this undervaluation but insist that full-time care by the mother is paramount for the child's psychological development. These contradictory messages mean that, whatever choice she makes, a woman psychiatrist is seen to be wrong. There were also the more obvious constraints imposed by the career structure and the scarcity of appropriate child care. In the group we were able to discuss both what we ideally wanted, and make realistic choices from the more limited range of options available. Another way in which the group enabled us to challenge widespread attitudes to women was by increasing our confidence. We believe that women often come to feel that they are second-class and entitled to less than men. Although 
we recognised that we often had to balance competing demands, this did not mean that we were less skilled or had less to offer.

Our success shows that a support group can be sustained, despite demands on time. It succeeded for several reasons; through the Women's Therapy Centre we had access to the skills of a facilitator initially and at times of difficulty; our membership was relatively stable and highly motivated; finally, as women, we found it easier to accept the need for support.

Participation in a successful group made us reflect on support within psychiatry. Although individual psychiatrists receive support from various sources, there is no generally recognised support system. This is worrying since our working lives are largely spent caring for others, and dealing with profound distress. At times the profession seems to imply that only the weak or inexperienced need support. Perhaps this stems from understandable fears of appearing needy, which the seductive image of the omniscient medical scientist so emphasised in training does little to dispel. Such attitudes, however, diminish staff and patients alike.

\section{Further reading}

EQUAL OPPORTUNITIES COMMISSION (1982) Caring for the Elderly and Handicapped: Community Care Policies and Women's Lives.

Kaufman Cartwright, L. (1987) Occupation stress in women physicians. In Stress in Health Professionals (eds R. Payne and J. Firth-Cozens). Chichester: John Wiley.

KRzowsKI, S. \& LAND, P. (1988) (eds) In Our Experience: Running Workshops with Women. London: Women's Press.

MARgison, F. R. (1987) Stress in Psychiatrists (eds R. Payne and J. Firth-Cozens). Stress in Health Professionals. Chichester: John Wiley.

SCARR, S. \& DUNN, J. (1987) Mothercare/Othercare. Harmondsworth: Penguin.

\title{
Meetings for the relatives of refugees from Vietnam suffering from schizophrenia
}

\author{
M. J. BlaCkwell, Senior Registrar in Psychiatry, St Thomas' Hospital, London SE1; \\ formerly Research Registrar, Department of Psychiatry, UMDS, Guy's Hospital \\ (Correspondence to Department of Psychiatry, UMDS, Guy's Hospital, \\ London SE1 9RT)
}

The problems of diagnosis in transcultural psychiatry and the ideological and anthropological questions raised have received much attention in the psychiatric literature over the last 15 years. Even when the diagnosis is not in dispute, specific problems are encountered in the delivery of psychiatric care to patients from ethnic minorities (Littlewood \& Lipsedge, 1989; Rack, 1982). Different explanatory models of illness and treatment, linguistic and cultural misunderstandings and numerous, apparently minor, practical difficulties bedevil treatment. Contributions to the psychiatric literature of practical use in management and service designs have been sparse.
In 1985 evidence given to the Home Affairs Committee of the House of Commons indicated an "alarming incidence" of psychological problems among refugees from Vietnam (this was not quantified however). It was suggested by the committee that a special service be set up. Our service and the meetings they have produced have been an attempt to meet this need.

\section{The problems}

In London, it is estimated that there are 12,000 refugees from Vietnam (British Refugee Council, 1987). The cultural and linguistic diversity of 